\title{
A generic knowledge management approach towards the development of a decision support system
}

\author{
Oussama Meski $\mathbb{1}^{\mathrm{a}}$, Farouk Belkadi $\mathbb{1}^{\mathrm{b}}{ }^{\text {, }}$ Florent Laroche ${ }^{\mathrm{b}}$, Mathieu Ritou ${ }^{\mathrm{a}}$ and Benoit Furet ${ }^{\mathrm{a}}$ \\ ${ }^{a}$ LS2N (Laboratory of Digital Sciences of Nantes, UMR CNRS 6004), University of Nantes, Nantes, France; b ${ }^{L} 2 \mathrm{~N}$ (Laboratory of Digital Sciences of \\ Nantes, UMR CNRS 6004), Centrale Nantes, Nantes, France
}

\begin{abstract}
The fourth industrial revolution is increasingly implemented in most fields and categories of industry. The use of several highly developed technologies generates huge amounts of heterogeneous data and knowledge, hence the need to manage it in order to facilitate its reuse. This article proposes a global approach of knowledge management, from the analysis and development of the knowledge base structuring models, to the implementation phase using knowledge engineering tools. This research work is part of a global knowledge-based decision support framework that ensures several axes of decision support, this article deals with the diagnosis axis. It provides analysis and comprehension of the failures occurring during production. The approach has been implemented as a first demonstrator tested in a real case study: the aeronautical mechanical machining industry. This article details the issues of this implementation and its interest for the validation of the approach.
\end{abstract}

\section{Introduction}

Since its appearance, the fourth industrial revolution has not ceased to affect most fields of activity and its implementation presents an interesting research topic in several disciplines. Nowadays, the strong aspect of this revolution is the expansion of the industry with the use of several technologies such as cyber physical systems, Internet of Things, digital twin, etc. (Zuehlke 2010).

Production systems are among the most favourable areas for migration to industry 4.0 because manufacturing industries aim to provide an optimal and efficient product for their customers while maintaining as a main challenge the increase of competitiveness and the improvement of productivity (Brynjolfsson, Hitt, and Kim 2011). Thus, these systems continue to work daily on findi $g$ the best tips and tools for continuous production improvement.

Despite the emergence of new technologies and their ability to solve industrial problems, these tools need to remain under the control of the technicians and must be managed by human capacities and skills. The expertise of all industrial actors is crucial to ensure optimal use of available resources. This collaboration is the origin of artifici 1 intelligence, which can be considered as the digitisation of human know-how, skills and experience in order to automate the process of proposing solutions to reduce calculation times and reasoning efforts. Among the methods of artificial intelligence, decision support systems (thereafter, DSS) are used to analyse a problematic context and to propose a suitable solution to correct or avoid it (Teti 2015). These techniques have been too widespread for years and their usefulness is increasing with the appearance of new information technologies. As long as these systems are based on business rules and industrial knowledge bases, they will generate reliable results.

Given all the resources used in industry, huge amounts of data and knowledge are available but unfortunately not widely exploitable. It is obvious that their reuse is constrained due to the heterogeneity of this knowledge. Several researches deal with the knowledge reuse issues in the field of production and manufacturing (Cochrane et al. 2009; Chungoora et al. 2013; Urwin and Young 2013): they all agree there is a need for a process of knowledge structuring and management in order to facilitate their exploitation.

This research work focuses on a specifi fiel of production: the machining of aeronautical mechanical parts. As these parts are very expensive and complex, the challenge of productivity is to manufacture good parts from the first try. Implicitly, it is necessary to avoid the occurrence of any problems or malicious phenomena that may affect the machining process (Teti 2015). Therefore, it's important to monitor the machining process (Ferretti 
et al. 2013) to improve its quality and its efficie y (Psarommatis et al. 2019).

In addition to the two methods studied in this research, DSS and knowledge modelling and management approaches, the improvement of the performance of the manufacturing process can also be achieved through improving sustainability metrics (Raman et al. 2020). Several standards are working on characterising industry manufacturing processes for sustainabilityrelated decisions. For example, the subcommittee E60.13 of the American Society for Testing and Materials (ASTM) is focused on the issues of sustainable manufacturing.

This article proposes an industrial knowledge management strategy to help the development of a decision support system. The global framework being developed enables several decision-support axes: reporting, diagnosis, prediction and reaction. This work is mainly focused on the second axis.

Therefore, this article begins with a literature review on decision support systems and knowledge management. Next, the first steps of the approach construction are presented; they consist of data and knowledge analysis and modelling. Finally, the scientific proposal ends with the presentation of the usefulness of the knowledge management approach for the development of the second decision support axis: diagnosis.

\section{State of the art}

This literature analysis begins by definin decision support systems, describing their usefulness, and detailing their processes. There are several categories of such systems, among them those based on knowledge management processes. The knowledge, as well as the tools and methods needed for its structuring and management will be described in the second part.

\subsection{Decision support systems}

Research around designing technological solutions capable of supporting decision-making assistance to solve problems began since the 1970s (Gorry and Scott Morton 1971). The DSS consists of developing and implementing systems using information and communication technologies to ensure decision-making (Shim, Warkentin, and Courtney 2002). The DSS are very useful for improving and facilitating management at the different decision levels in the industry: the strategic level, which focuses on long-term planned actions to enhance productivity, the tactical level that manages processes and resources, and the operational level for the control and management of specifi operations (Klement, Silva, and Gibaru 2017).

\subsubsection{The DSS process}

Drucker (1958), Simon (1959) and Archer (1980) define three essential phases of the decision-making process. The first is 'the intelligence phase' which mainly deals with the definition of the problem. The second, intermediary, for structuring and defining the links between problems and proposed solutions 'the design and modelling phase'. Finally, 'the choice phase' allows the decision-making and the proposal of a validated final solution.

Based on these 3 phases, several other works continue to define the steps of the decision support process, and the most frequently cited research remains that of (Shim, Warkentin, and Courtney 2002) which defines seven steps. The fi st is always the problem identific tion. For each issue, there is one or more method to eliminate or avoid its occurrence. To analyse these different alternatives, it is important to develop specific models that define the relationships between issues and proposed solutions as well as all the complementary parameters and business rules. These intermediate steps of analysis make it easier to choose the appropriate decision to be able to implement it in the last step.

\subsubsection{Different categories of DSS}

Along the technological evolutions, and the development of research on DSS, this field greatly evolved and several approaches and subfield emerged over time. Arnott and Pervan (2005) deals with DSS and defines the main subfield and their evolution over time. It is hence possible to describe some types of DSS:

- Personal Decision Support Systems: as the name implies, these are often developed for a single manager or a group of independent managers.

- Group Support Systems: are developed to improve the work and collaboration among a working group. The main objective of this system is to encourage decisionmaking based on all the suggestions proposed by the various members of the group.

- Negotiation Support Systems: this type of system uses computer technologies to facilitate negotiation. There are two categories of these systems: problem-oriented and process-oriented.

- Intelligent Decision Support Systems: this category of system introduces the use of artificia intelligence in decision support. They are classifi d into two generations: the fi st is rule-based systems and the second generation includes genetic algorithms, fuzzy logic and neural networks.

- Knowledge Management-Based DSS: these systems allow the taking based on the capitalisation of knowledge and the development of knowledge repositories. 
Also the manipulation, transfer and reuse of knowledge, for the purpose of decision-making and thus the creation of new knowledge.

The Decision Support System developed throughout this research work can be classified as both an Intelligent DSS and a Knowledge Management-Based DSS as it focuses on capitalising knowledge and expertise thanks to artifici 1 intelligence.

\subsection{Knowledge management (KM)}

Before beginning the management process, a literature review was essential, particularly concerning knowledge definitions. Davenport and Prusak (1998) define knowledge as:

A fluid mix of framed experience, values, contextual information, and expert insight that provides a framework for evaluating and incorporating new experiences and information. It originates and is applied in the minds of knowers. In organizations, it often becomes embedded not only in documents or repositories but also in organizational routines, processes, practices, and norms.

Since the 1990s, many researchers have become strongly interested in knowledge management strategies as these methodologies has become crucial to increase productivity and competitiveness in production industries. Knowledge management can aff ct the organisation in several aspects: its structuring, behaviour, resources, and even organisational and economic strategies. Concerning DSS, several works have focused on the importance of KM to facilitate decision-making and to support knowledge creation processes (Carlsson and Lundberg 2000; Carlsson et al. 2000; Alavi and Leidner 2001; Iaksch and Milton Borsato 2019).

Nowadays, with all the aspects of development and progress achieved, the challenge is not limited to the use of an effici $t$ information system and developed technological resources: the real issue is to be able to adapt these resources to facilitate the creation of knowledge. (Gunasekaran and Ngai 2007; Chow et al. 2005) defin knowledge management as the set of operations and activities that enable the creation and storage of knowledge for its distribution and application in organisations. In the same context, research continues to defin the basic functions of the knowledge management process. In 2017, Olson and Wu dealt with the $\mathrm{KM}$ processes in the service of the DSS and distinguished the following 4 core functions: the identification of the most important information and measures to support the decision-making, the acquisition of the data corresponding to these measurements and the storage in specifi databases for allowing the retrieval (Olson 2018).

Using $\mathrm{KM}$ is very important in several field and especially in production and manufacturing. Berawi and Woodhead (2005) confi $\mathrm{m}$ that a good KM strategy helps to improve the overall production management system. Several research works deal with these themes in all the stages of the production process: purchasing (Lau et al. 2005; Zsidisin, Melnyk, and Ragatz 2005), planning (Gernhardt et al. 2016; Miltner, Vogel, and Hemmje 2014; Efthymiou et al. 2015), scheduling (Kant and Sridharan 1998; Chryssolouris et al. 2008), quality control (Muthu et al. 2001), etc.

In the field of manufacturing and production, and more specifical y in the mechanical machining domain, the analysis of the available data and knowledge allows the distinguishing the heterogeneities due to the variability of sources, types, natures, frequency, etc (Grevenitis et al. 2019). Thus, a challenge of adaptability and structuring is key to enable the aggregation, processing and extraction of knowledge from these information flows (Farhoomand and Drury 2002). Research on data and knowledge in the fiel of production has generally focused on the basic objects that compose the industry, i.e. the product, the resources used, the manufacturing process, the work context, the behaviour, etc. The modelling of industrial data and knowledge revolves around these basic objects. The analysis of the literature helps to distinguish several modelling approaches, for instance: The Product, Process, Resources approach (CuttingDecelle et al. 2007; Borja Ramis et al. 2016), The Function, Behaviour, Structure - Product Process Resource External Effects approach (Labrousse and Bernard 2008).

Knowledge modelling must ensure a better visibility and understanding of the industrial knowledge $\mathrm{fl}$ ws to the expert (Demoly et al. 2010). It is therefore essential to propose a well-structured and rich representation by adding semantics to relations and objects (Belkadi et al. 2012). Studies in the fiel of semantic modelling are, generally, connected to the semantic web (BernersLee, Hendler, and Lassila 2001). Hence the use of its languages, generally developed by The National Institute of Standards and Technology (NIST) for example: RDF (Resource Description Framework), XML (eXtensible Markup Language) and OWL (Ontology Web Language) (McLean et al. 2005; McGuinness and Harmelen 2004).

Among the most effective methods for ensuring semantic understanding are ontologies (Pavel Vrba et al. 2011). An ontology is a method for representing and organising knowledge of a specifi field using reasoning and inference mechanisms (Octaviani, Pranolo, and Othman 2015; Munir and Anjum 2018). 
Gruber (1993) which define ontology as an explicit specification of a conceptualisation, he also describes all of its fundamental elements:

1. Concepts or classes: these notions allow the description of a task, a function, an action or a reasoning process.

2. Relationships: represent a type of interaction between two or more concepts. Examples of relations include 'subclass-of' or 'connected-to'.

3. Functions: are a special case of an n-element relationship where the last element of the relationship is unique for the fi st n-1 elements.

4. Axioms: are used to defin the semantics of terms (classes, relations), their properties and any constraints regarding their interpretation.

5. Instances: used to represent elements.

Two types of ontologies can be distinguished: storage ontologies and inference ontologies (Fankam 2009).

The first, as its name suggests, allows to capitalise a maximum of knowledge on a given domain. The second allows, through the execution of a set of business rules, inference rules, restrictions and constraints, the automatic generation of new knowledge (Milicic et al. 2013).

Ontologies are used in several domains to ensure communication, structuring and reuse of knowledge (Gruninger and Lee 2002; Sureephong et al. 2008; Schmidt et al. 2016). And to ensure interoperability (Gunendran and Young 2007) between the different subcomponent of an overall system. Thus, they are a good choice for the development of knowledge-based systems (Sanya and Shehab 2015). In each particular fiel , research work uses reference ontologies (Annamalai et al. 2011; Borsato 2014) which are considered highly generic domain ontologies, often resulting from merging several specifi ontologies (Palmer et al. 2018). In the literature there are several examples of these reference ontologies, such as: DOLCE (Masolo et al. 2004; Sanfilippo and Borgo 2015) SUMO (Oberle et al. 2007) BFO (Robert Arp, Smith, and Spear 2015). Some ontologies are more specifi to the manufacturing domain such as MASON (Lemaignan et al. 2006), Onto-pdm (Panetto, Dassisti, and Tursi 2012), etc.

Others have used standards for the development of ontologies, for example: OntoSTEP (Krima et al. 2009) based on the Standard for the Exchange of Product model data (STEP). Also, standard languages such as The PSL ontology based on The Process Specific tion Language (Schlenoff et al. 2000; Gruninger and Kopena 2005). There is also the Standard MTConnect that, according to their website, 'off rs a semantic vocabulary for manufacturing equipment to provide structured, contextualized data with no proprietary format'.

There are several foundations whose objective is to centralise research on ontology development in each specifi field. In the area of digital manufacturing, the Industrial Ontologies Foundry (IOF), as stated on their website, tries to create a set of core and open reference ontologies that spans the entire domain (Kulvatunyou et al. 2018).

After the analysis of the ontological solutions proposed in the literature, and considering their interests for ensuring interoperability and communication of knowledge between the services of industry, it is noticeable that most of these works are oriented towards partial communication. It is insured just between the services directly involved in the realisation of the product: basically between the workshop and the design or manufacturing departments. This implies a lack of communication between the different services of the industry, which are closely or remotely related to the realisation of a product as well as the communication between the different information systems of the company. In addition, the proposed solutions do not manage all heterogeneous knowledge from different sources and formats. Another disadvantage is the lack of genericity of the identifi $d$ solutions. This involves a difficult reuse in other fields compared to our ontological solution, which enables flex ibility and adaptability, thanks to its layered structure and the use of norms and standards.

This literature review raises three main issues: how to develop the best knowledge management approach, able to structure the variety of heterogeneous data and knowledge? How to implement such a knowledge repository? How to exploit it, to ensure the reuse of knowledge and to generate new ones in decision-support scenarios?

\section{The analysis phase}

A clear distinction between the different types of heterogeneous data and knowledge circulating in the industry is necessary for optimal capitalisation.

In order to build this classific tion of knowledge, the first step adopted in the proposed methodology was to develop process models to analyse all information flows in the manufacturing shop floor of mechanical parts. They were built based on literature survey and consolidated with the industrial partners of this research project in order to validate the adequacy of these formalised manufacturing processes (Meski et al. 2019b).

In addition to the output data flows generated from the various phases of product manufacturing, monitoring data are also traced using a specifi device composed of hardware components (such as sensors and acquisition 
cards) and software components that include monitoring database and processing algorithms.

Several sensors have been installed to monitor machining parameters: acceleration, temperature, vibration frequency, etc. These sensors allow the recording of representative data concerning the health status of the machine and its different components (spindle, cutting tools, platens, etc.). The machine's computer numerical control (CNC) provides additional information related to the operational context of manufacturing process (date and time of operation, working piece reference, program reference, operating mode, etc.). These heterogeneous data are then subjected to several aggregations and data mining operations to generate a new category of data called Smart Data (Ritou et al. 2019). The use of these processing methods adds a new semantic layer representing links between the initial raw data. New indicators are then created and allows for better evaluation, not only of the health status of the manufacturing resources, but also the quality of the manufactured workpiece and especially the potential malicious phenomena that may appear during machining process. Both the use of smart data and key performance indicators (KPIs) require additional knowledge from the expert who therefore acts like an additional knowledge source.

The capitalisation of this different knowledge allows the implementation of several decision support scenarios (Figure 1). The first axis is the 'Reporting' which provides several reports that describe malicious phenomena conducted to undesired impact (i.e. a degradation of the quality of the working piece due to the appearance of a chatter, a cutting tool breakage, a collision between the tool and the part, or others). These reporting operations are executed within a specifi mode (periodic, on-demand, after a phenomenon occurs) and are customised for particular business roles or departments in the company (quality control, maintenance, process planning, programmer, etc.). After reporting and studying the characteristics of detected problems and phenomena, a diagnosis process must be carried out to detect the cause of their appearance. Finally, once the situation has been studied, solutions can be proposed to facilitate the decision-making process to improve the product quality or to prevent any future occurrences.

The separation between data and knowledge types conducts to two repositories. The first one includes raw and smart data (separated in three databases) while the second gathers all the available industry knowledge, the business rules, the set of KPIs and reports generated through the reporting processes. Thus, the four knowledge types distinguished in this work are raw data base, smart data base, traceability data base and knowledge repository (Meski et al. 2019a).

To structure these digital repositories, several categories of models have been created. First, data models were dedicated to clarify all the available industry data

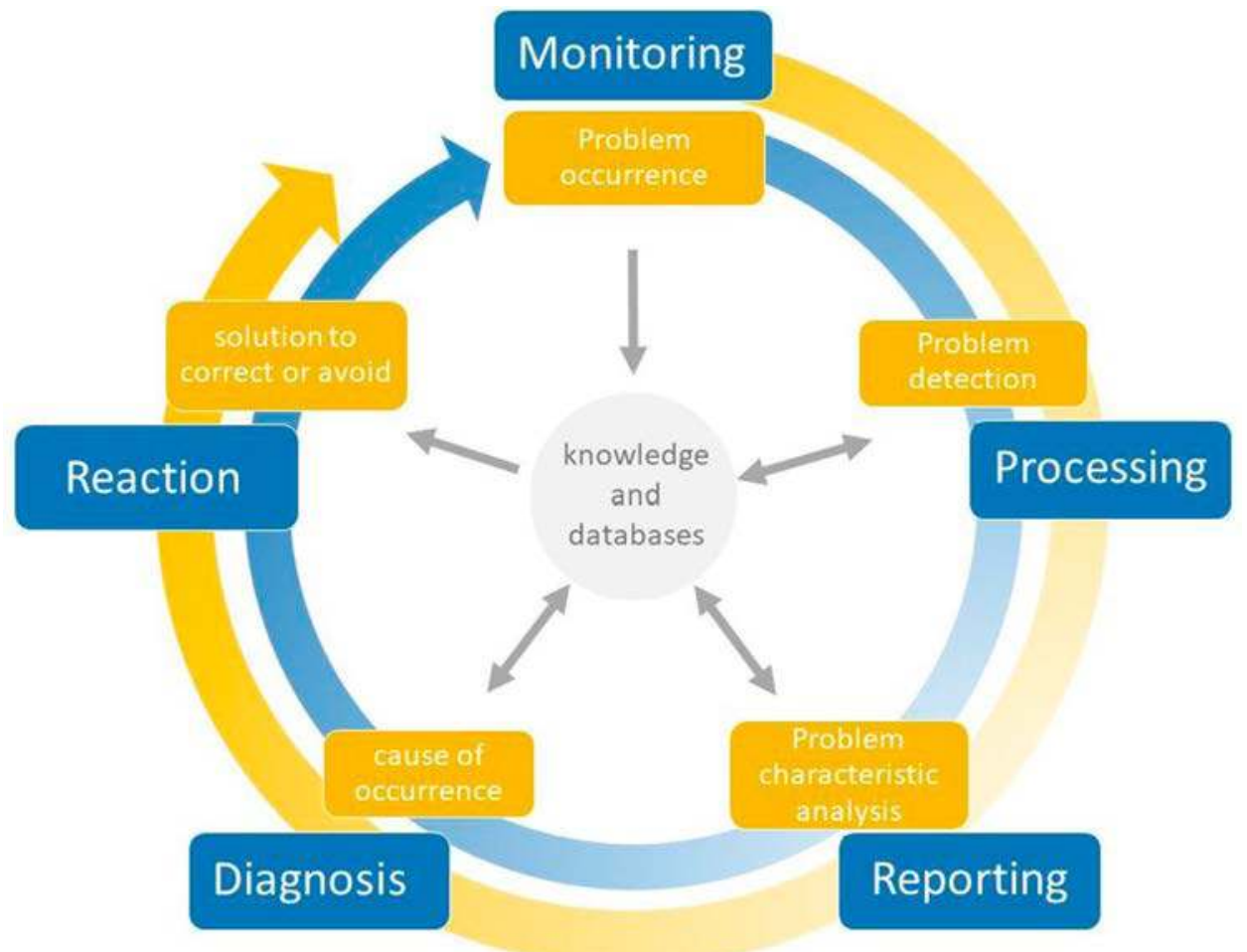

Figure 1. Execution phases analysis. 
fl ws, in a standard format, then other models were developed to structure the traceability database.

\section{Data-knowledge models construction}

Before starting construction of the models, an in-depth study of the state of the art in the fiel of product and process-oriented modelling was made and coupled with an analysis of real industrial processes. The target was to draw inspiration from the models realised in the fiel . Following this literature review, several modelling approaches were identified. These models are strongly linked since they are all based on a common list of industrial objects and components. Among these components were identified four that match well with this project: product, process, context, resources, and people. While these objects represent essential elements for each industry and they are considered fundamental to model the global industrial knowledge base, previous modelling approaches do not cover all of these elements simultaneously. This leads to the development of the CR3P (Context, Resources, Product, Process, People) modelling approach. As its name suggests, it initially covers the entire context of the work and the whole set of significant knowledge that can cover information about working conditions, references and identifie s of the different elements used, as well as information about risk assessment or even the constraints imposed by the end customer. This approach also involves knowledge related to the resources used, the product being manufactured or the process followed to manufacture it (Meski et al. 2019b).

The specific ty of the approach is also linked to the integration of the 'People' object as a foundation element in the global knowledge model. The CR3P approach emphasises the human by considering it as a main node of the overall industrial structure. An important amount of knowledge is provided by the expert and several decisions must be taken or supported by him and his expertise. This expert knowledge lies in what is called business rules.

Based on the analysis step, the knowledge models have been developed and enriched with high level of granularity and details using ontology modelling paradigm. Indeed, using ontologies is a practical solution given the large amount of heterogeneous knowledge to be considered, the relations and business rules to be integrated, and the reasoning to deduce new knowledge and decision to be created.

The proposed ontology is structured around several layers, gathered into three main groups, which have been formalised according to the specific ty, nature and origin of the knowledge acquired (Figure 2).
The first layer contains the dictionaries of resources used in machining process, such as references of the cutting tools used with their specific cutting conditions, characteristics of the resources used for manufacturing, types of raw materials used. There is also the knowledge related to the manufacturing process, the diff rent operations used, etc.

In parallel with this fi st layer, and in order to ensure the genericity of the knowledge base for future reuse in other fields, norms and standards have been analysed and the most appropriate ones have been considered for structuring the second layer of ontological models. In this research, part of the STEP-NC (14649-10: Data model for computerised numerical controllers - Part 10: General process data) is used. It includes all the parameters, names, concepts and relationships for the majority of manufacturing operations and features. STEP-NC is a data exchange standard for numerical control programming, and for communication between the diff rent parts of the physical industrial chain: design, industrialisation and manufacturing. It is based on the STEP standard (STandard for the Exchange of Product model data) that use the data modelling language EXPRESS to develop several models and schematics. In addition, Step NC uses the graphical standard EXPRESS-G to represent the process model. This standard is widely used in the field of mechanical manufacturing.

The integration of this standard into the global knowledge base consists of transforming EXPRESS-G diagrams into an ontology composed of classes, relationships and attributes. The transformation of this standard into the ontology has resulted in the development of more than a thousand axioms (Figure 3).

The last layer groups all the knowledge necessary to support the decision process. It includes mainly business rules and the structure of a decision support case. In this research work, the business rules are very useful and essential for the implementation of the second development axis in this project: the diagnosis. As shown in the figure above, the three layers constituting the ontology are strongly interlinked. In general, the execution of a decision support scenario should begin by analyzing and identifying the context elements, characterising the situation or case to be treated. They are instantiated based on dictionaries and sometimes-standard layers.

Data and knowledge bases are in continuous collaboration: the execution of a scenario starts at the knowledge base level to retrieve the necessary structure then the reasoning system queries the databases to retrieve the corresponding data. The processing is then executed and it instantiates specifi elements in the knowledge base. For an event diagnosis scenario, these elements, also known as individuals, are represented by cases and those 


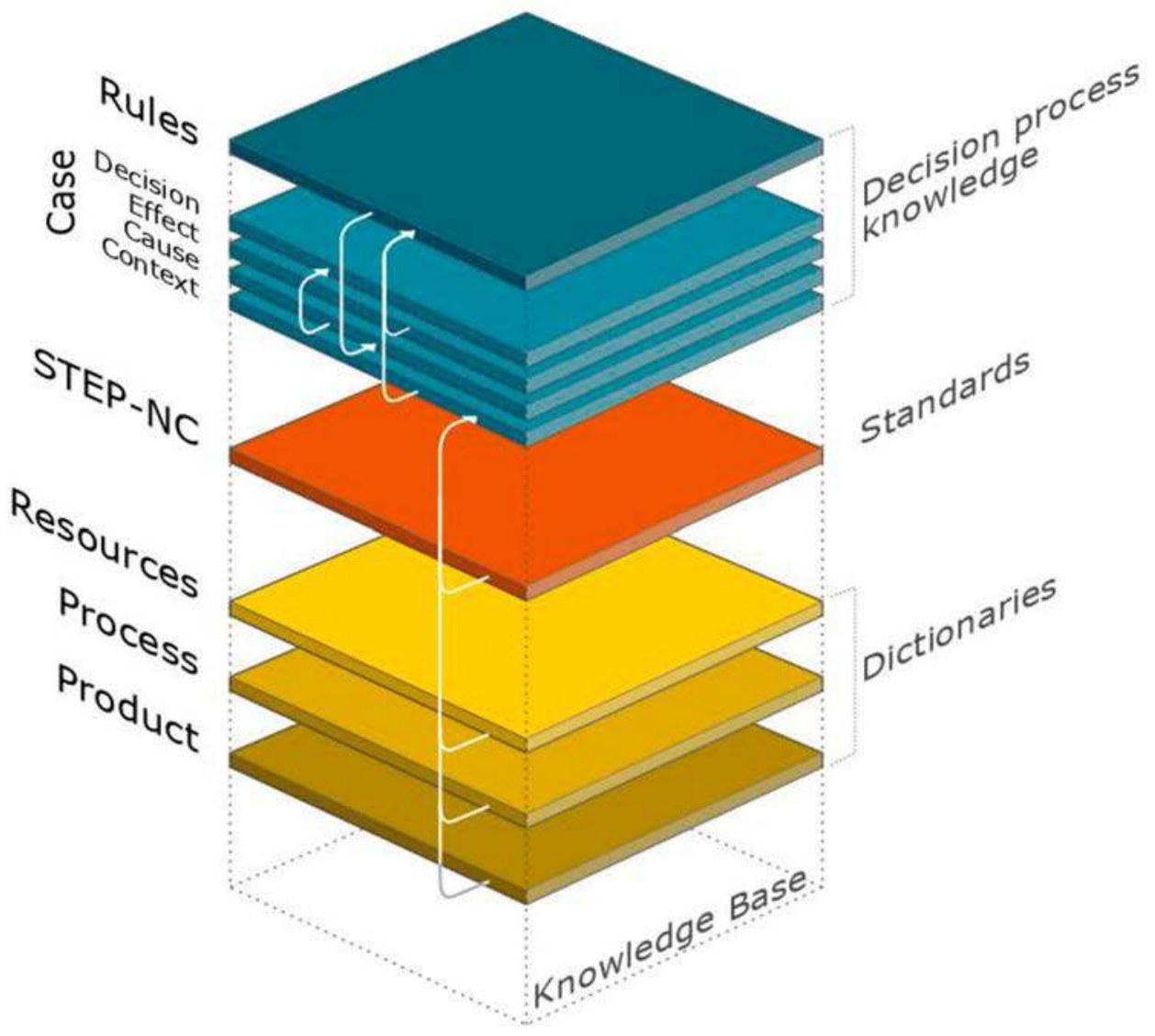

Figure 2. Knowledge base structure and layers interconnection.

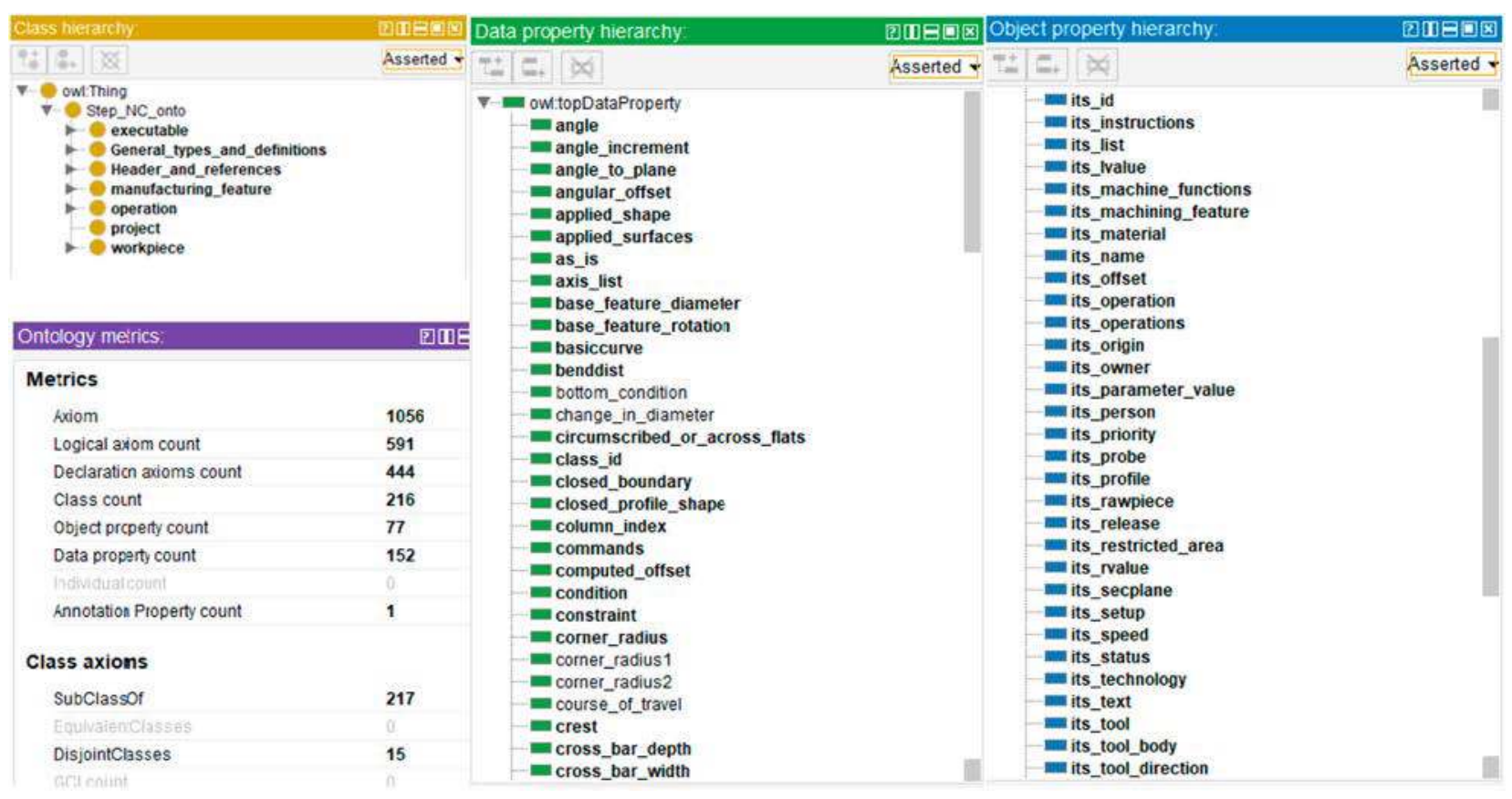

Figure 3. STEP-NC from Express-G to ontology with Protégé software. 
are structured with the objects 'cause, effect, decision, context', which will be presented in the following section.

\section{Framework application: the diagnosis process}

In order to improve a company's productivity and competition, a diagnosis process is set up. It allows the analyse of distinguished failures and the detection of the causes of malicious phenomena appearance during machining process. Beyond that, the diagnosis scenario is based on a characterisation of the working context to propose the appropriate solution based on experiences. This will help improving quality and leading time of the entire production process, and especially to lighten the work of the quality department. The proposed solution aims also to support the maintenance department to be preventive and avoid the recurrence of similar undesirable phenomena in the future.

\subsection{Proposed approach to diagnosis process}

At the conceptual level, the proposed approach is based on the well-known FMEA (Failure Modes and Effects Analysis) method in order to set up the main criteria and parameters representing failures, causes and eff cts. Following this method, new knowledge (rules and procedures) has been integrated into the ontology in order to support the diagnosis process at the decision aid level. This knowledge is structured as a 'case' which is composed by the quadric 'Context-Cause-Effect-Decision'.

- The CONTEXT calls, from the other layers of the ontology, all the elements necessary to characterise the manufacturing environment, namely: the name and reference of the tool, the name of the program and subprogram, the date, etc. Additional characteristics of the machining resource can be reached from the resource library. These contextual elements depend strongly on the diagnosis case and can vary according to the related decision needs of the user.

- The EFFECT characterises the main failure to be diagnosed. In this project, it represents the malicious phenomenon that has appeared. The instantiation of this element can be either automatic following a direct detection of the problem or indirect following a fi st phase of in-depth analysis. This object has several features and options, namely: an effect can be the origin of another one, each effect can be generic or detailed, an effect can also be an element of context for another case, etc.

- The CAUSE is the key element of the proposed knowledge-based diagnosis approach. It represents the origin of the malicious events that occurred during the machining of a mechanical workpiece. To be able to propose a cause to an event, the solution was to formalise human intelligence and the best practices in order to propose an artificial intelligence tool ready to be integrated into the machine. More precisely, in this project a set of business rules have been defin $\mathrm{d}$ to formalise the interpretation of expert about past incidents. So, the reasoning on the current incident can be made based on its connection to similar past situation were the appropriate business rules are applicable. The execution of business rules depends strongly on the contextual elements and the observed effect to generate the most reliable cause, hence the importance of the instantiation stage of the object 'context'.

- The DECISION: once a new undesirable situation has been detected, its effects observed and its causes identified, the last elements to be computed is a proposed solution and the related decisions needed to solve the problem. The notion of decision (or solution) includes all actions beyond the diagnosis process that aim to remove the observed consequences (reparation) or to anticipate/neutralise the problem causes (preventive). Explicitly, it regroups all the rules, actions and procedures that contribute to reset or maintain the manufacturing system in its normal working conditions. Given the specificity of this research work, the decision is represented by a solution, but it may have different forms in other cases of application, depending on the objective, and the need of the user. Therefore, the loop of the knowledge-based decision-aid framework is closed.

The global objects of the modelling strategy represented by the quadric defined above, are strongly linked and can depend on each other. More precisely, a first phenomenon 'A' (represented by an 'Effect1' with a 'Cause1') can be the cause of appearance of a second phenomenon 'B' (an 'Effect2' with a 'Cause2'), as shown in the Figure 4 , and this induces a second diagnosis process.

More formally: « Effect $1 \rightarrow$ Cause $1=$ Effect $2 \rightarrow$ Cause2»

In this case, the context may be the same for both scenarios (referred as 'ContextGlob') or may be specifi to both (referred as 'Context1' and 'Context2'). More formally:

Either: $\exists$ ContextGlob in which « Effect $1 \rightarrow$ Cause $1=$ Effect $2 \rightarrow$ Cause $2 »$

Knowing that $\{$ Cause1, Effect1, Cause2, Effect2 $\} \in$ ContextGlob

Either: $\exists$ (Context1; Context2) $\in$ ContextGlob

Such as « Eff ct $1 \rightarrow$ Cause $1=$ Effect $2 \rightarrow$ Cause2 $»$ 


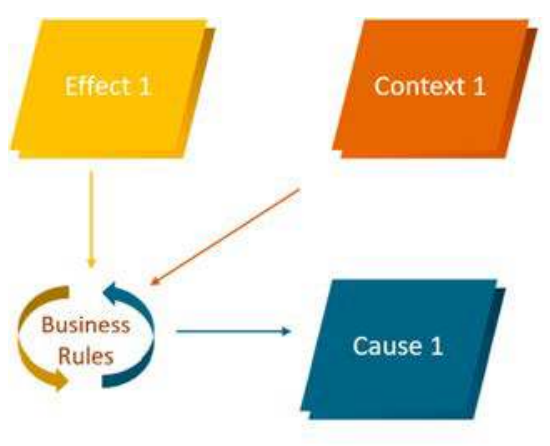

=

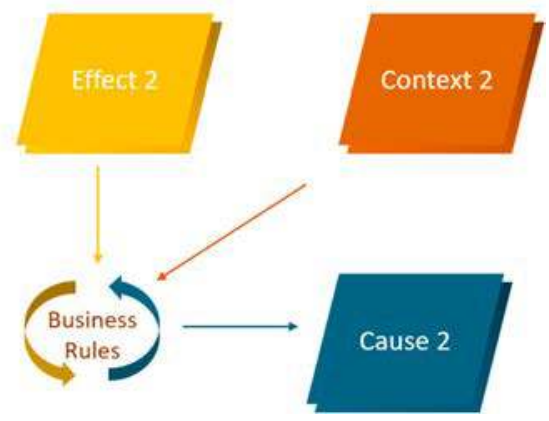

Figure 4. Dependencies of diagnosis elements.

Knowing that $\{$ Cause1, Effect 1$\} \in$ Context1

$\{$ Cause2, Effect2\} $\in$ Context2

More technically, in order to structure diagnosis operations at the ontology level, these four objects have been defin $\mathrm{d}$ as classes. In addition, a list of relationships linking these classes and attributes has been specified. Progressively, as the ontology is implemented and real scenarios are run, these classes will be instantiated by creating the corresponding group of individuals. This instantiation is based on previously structured industrial databases (raw, smart and traceability); this highlight the utility of the knowledge management strategy, promoting the interaction with data to generate new knowledge.

To better illustrate this structuring methodology, a use case scenario is presented in the next section.

\subsection{The use case}

The initial stage was made prior to this research work and concerns the defin tion of specifi data mining algorithms to analyse raw data and extract smart data (Wang et al. 2019). This leads to the generation of traceability data and the management of heterogeneous reports (Ritou et al. 2019). Together, these latter two publications explain the various operations required for the preliminary stage. Many research works define the criteria to be respected and the means to manage large-scale enterprise software systems. A multitude of technologies and standards exist to ensure software interoperability and systems integration in order to facilitate interaction with each other (Andersson and Johnson 2001).

In this research project, given the diversity of tasks, skills, and technologies handled by the different research teams, the need for a solution to ensure technical interoperability is necessary to develop a common global Framework. The solution chosen in this use case is the use of multi-agent systems. Thus, several agents have been developed over time (Computing Agent, Communication Agents, Databases Agent ...). In this article, a decision support agent is presented: the Diagnosis Agent.

\subsubsection{Expertise analysis and scenarios definition}

Operations of data mining were able to detect a set of very frequent phenomena: chatter, tool failure, and collision. To ensure this detection, a first phase of machine learning was established to calculate specifi thresholds for several detection criteria and parameters. For example, to detect a chatter, it is sufficient to notice an overflow of the threshold for the ' $\mathrm{N}_{\mathrm{h}}$ ' parameter which is the sum of the amplitudes of the fiv dominant non-harmonic contributions of the vibration spectrum (Godreau et al. 2019). A tool failure is also likely due to the exceeding of the threshold defin $d$ for the ' $U_{b}$ ' parameter which is computed as the vibration amplitude of the contribution at the spindle frequency, when the spindle is rotating without cutting (to prevent from false detection due to cutting forces). Several other aspects can be the cause of an abnormal phenomenon, such as significant power variations, which are good indicators of a collision. In addition, the variation of the machine-tool potentiometers is a practical KPI since it allows the detection of any human intervention that could delay productivity. After this first step of phenomenon detection, in order to understand the cause of appearance, a formalisation of all the business rules necessary for an analysis is essential. To realise this second step, the solution is to hold interviews with technicians and industrial experts and discuss possible causes. 
Table 1. List of possible diagnosis scenarios.

\begin{tabular}{|c|c|c|c|}
\hline Detection criteria & Effect & Cause & Rules \\
\hline $\mathrm{U}_{\mathrm{b}}>$ threshold & Tool failure & $\begin{array}{l}\text { - Cutting conditions problem } \\
\text { - Tool life badly defined }\end{array}$ & $\begin{array}{l}\text { Compare with reference cutting conditions } \\
\text { Tool often broken at the end of its life }\end{array}$ \\
\hline Power variation & Collision & $\begin{array}{l}\text { - Program error (during machining). } \\
\text { - Tool gauge or probing error. } \\
\text { - Wrong operator manipulation (manual mode) } \\
\text { - Problem returning the tool to the magazine }\end{array}$ & $\begin{array}{l}\text { Checking program and subprogram names (ex: CHANG_OUT.SPF } \\
\text { for tool change) }+ \text { machining time }=0 \ldots\end{array}$ \\
\hline $\mathrm{Nh}>$ threshold & Chatter & $\begin{array}{l}\text { - Either the tool or the workpiece } \\
\text { - bad programming } \\
\text { - bad workpiece clamping }\end{array}$ & $\begin{array}{l}\text { The recurrence of the phenomenon must be studied to understand } \\
\text { the origin of the phenomenon. }\end{array}$ \\
\hline
\end{tabular}

This leads to the defin tion of an explicit list of business rules. Table 1 shows some of them. On each line, parameters necessary to detect a given eff ct and the rules applied to determine its cause of appearance are detailed.

Following this mapping phase, an algorithm of the diagnosis agent is defin $\mathrm{d}$. It starts by an interaction with the user to define the specific context and the diagnosis operation to perform. The scenario category to be executed may depend on the user's profile, or on the importance and seriousness of the phenomena studied. Hence, the importance of defining a criterion or a criticality score for each anomaly. This rating is measured based on the following table (Table 2).

The diagnosis agent is in continuous communication with the knowledge base and databases. Accessing the knowledge base, it retrieves a list of criteria, conditions, thresholds, etc. Afterwards, accessing the databases it recovers data needed to execute the necessary specific reasoning. Finally, it instantiates all the case at the

Table 2. The measurement elements of the criticality criterion.

\begin{tabular}{lc}
\hline Criteria & Rating \\
\hline Failure severity rating grid G & \\
Minor defect without performance degradation & 1 \\
Fault can be repaired on site without performance degradation & 2 \\
Fault can be repaired on site with impaired performance & 3 \\
Non-repairable fault & 4 \\
Rating grid for the frequency of appearance F & 1 \\
Very low & 2 \\
Low & 3 \\
Frequent & 4 \\
Very frequent & \\
Non-detection rating grid $D$ & 1 \\
Effective preventive detection (measurement, optimised & \\
$\quad$ threshold, action) & 2 \\
Preventive detection (measurement, non-optimised threshold, & \\
$\quad$ action) & \\
Preventive detection not used & 3 \\
Not detected & 4 \\
\hline
\end{tabular}

ontology level with the context, effect, cause and decision respectively.

\subsubsection{General view of the algorithm}

To better illustrate these aspects, let's focus on a specifi scenario concerning the diagnosis of a tool breakage. Based on the previous list (Table 1), this scenario described in Table 3, will be treated.

The following diagram (Figure 5) represents the detection algorithm. It shows how the analysis of a particular scenario enrich the knowledge base, gradually improving the strength of this decision-support program.

\subsubsection{Technical aspects and user interface (UI)}

The Global Framework is developed using the Java language. The technological issue was to find the most suitable API to communicate with the ontology developed using the Web Ontology Language (OWL). The required solution is to use the Jena API. Apache Jena, as stated on the Jena website, is a Java framework to construct Semantic Web Applications. It provides a programmatic environment for:

- Resource Description Framework (RDF), a graph model for describing web resources and their metadata, so that such descriptions can be processed automatically. Developed by the W3C, RDF is the basic language of the Semantic Web.

- The Web Ontology Language (OWL), a knowledge representation language built on the RDF data model. It provides the means to define structured web ontologies.

- SPARQL Protocol and RDF Query Language, a protocol that allows searching, adding, modifying or deleting RDF data available through the Internet.

Table 3. The diagnosis scenario selected for the implementation.

\begin{tabular}{lcll}
\hline Detection criteria & Effect & Cause & \multicolumn{1}{c}{ Rules } \\
\hline $\mathrm{U}_{\mathrm{b}}>$ threshold & Tool breakage & - Cutting conditions problem & $\begin{array}{l}\text { Compare with reference cutting conditions } \\
\text { Tool often broken at the end of its life }\end{array}$ \\
\hline
\end{tabular}




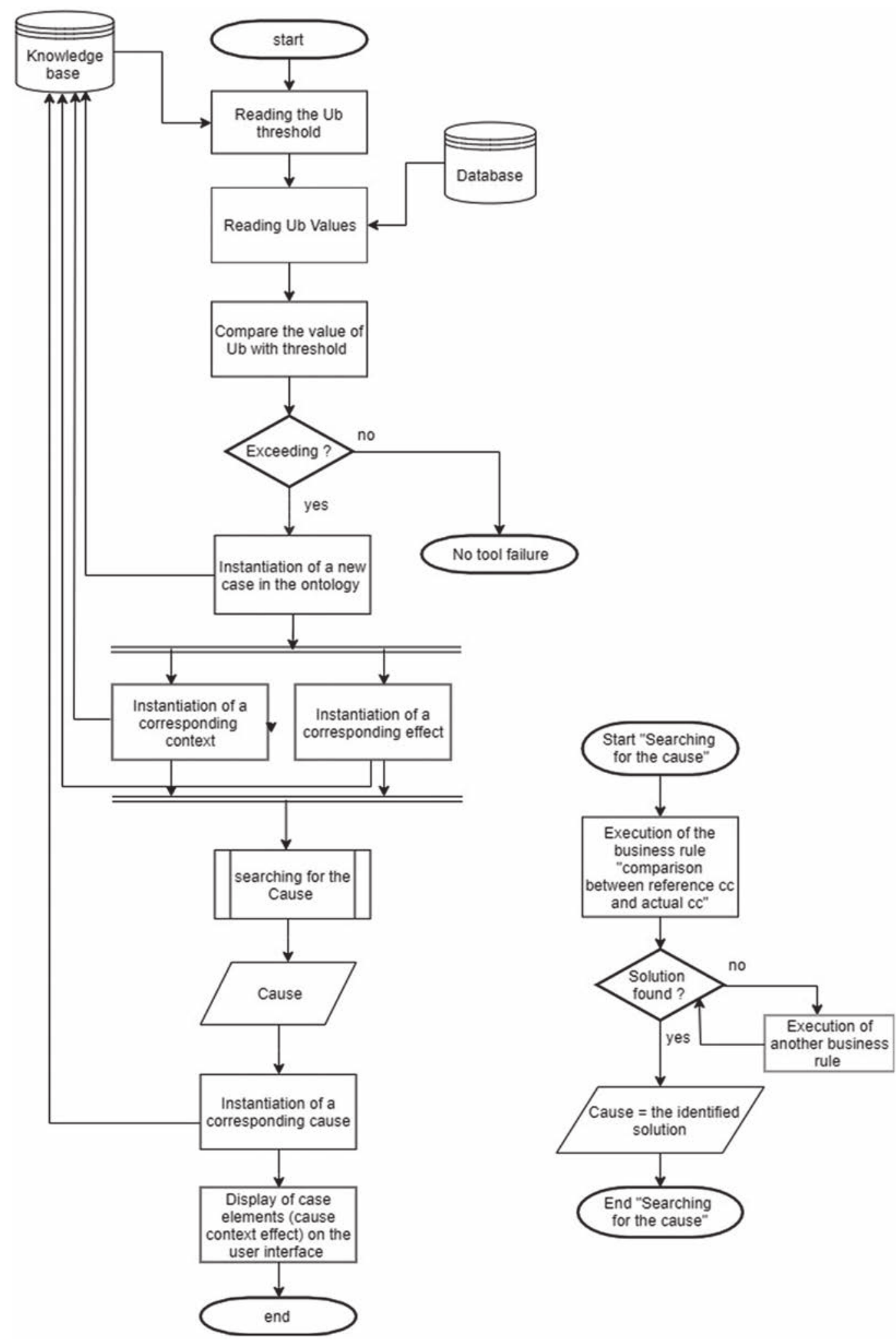

Figure 5. Detection algorithm flow chart.

- The Jena inference subsystem, designed to allow a range of inference engines or reasoners to be plugged into Jena. Such engines are used to derive additional
RDF assertions, which are entailed from some base RDF together with any optional ontology information, and the axioms and rules associated with the reasoner. 


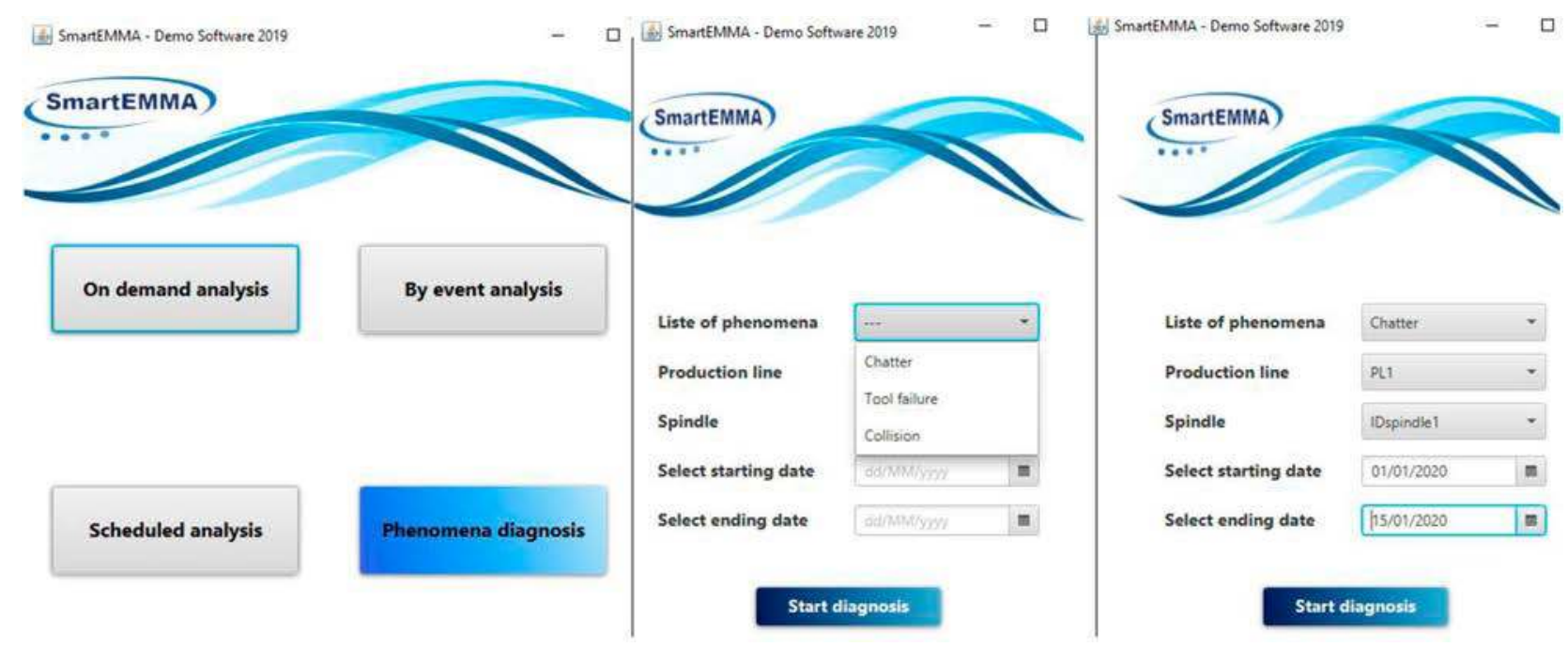

Figure 6. UI diagnosis launch.

These developments are part of a global demonstrator that revolves around two decision-support axes: reporting and diagnosis. On the first part of Figure 6 there are the 3 functionalities enabling to do reporting by event detection, on demand or by planning. Concerning this use case, the user has to choose the fourth, 'Phenomena diagnosis'. Thus, a second interface appears, in which he can choose from a list the context elements (production line, machine tool_Id, period, type of phenomenon to be diagnosed, etc.). In this scenario, the user chooses the 'Tool failure' phenomenon.

\subsubsection{Diagnosis process details}

In the specific scenario of a tool failure, the first step is the verification of the possible exceedance of the threshold defin $d$ for the detection criterion ' $U_{b}$ '. To do this, a threshold, calculated using machine learning algorithms, has been instantiated beforehand at the knowledge base level. This is the first manifestation of interaction between data and knowledge.
The querying of the ontology for data retrieval is done using the SPARQL query language. The figure below shows an example of a query used in this demonstrator (Figure 7).

Once the threshold value is recovered, the monitoring databases must be analysed by comparing the $\mathrm{U}_{\mathrm{b}}$ variations with this threshold. An exceeding value means the appearance of a tool failure and thus initiates the diagnosis process. Currently, the smart database is in form of a CSV fil . Figure 8 shows an excerpt from a smart data fil .

The instantiation of the ontology starts with a new individual (Figure 9) called 'Case_tool_failure' and also individuals of type 'Cause' 'Context' and 'Eff ct'.

Subsequently a mapping phase is needed to make the link between these elements using 'Object properties'. And finally, by using 'Data Properties' the attributes of each individual are added.

In order to add the context elements (considered here limited to the instantiation of the tool, the program and the day), it is necessary to position on the line containing

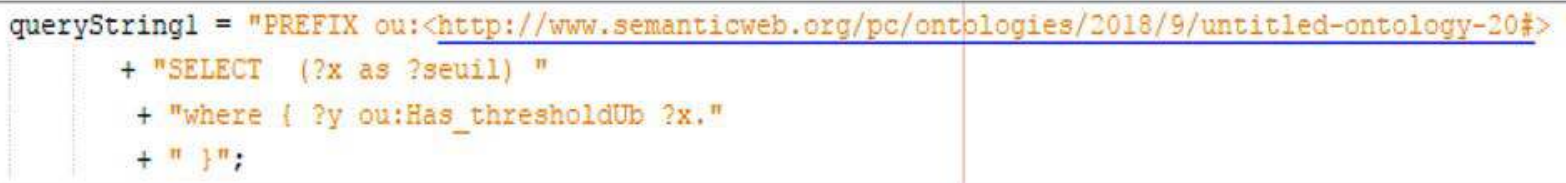

Figure 7. SPARQL query example.

\begin{tabular}{|c|c|c|c|c|c|c|c|c|c|c|c|}
\hline 4 & $\mathrm{~A}$ & B & C & D & $E$ & $\mathrm{~F}$ & G & $\mathrm{H}$ & 1 & $J$ & K \\
\hline 1 & Jour & ModeCN & progC & ID_Outil & OutilpF & temps_total & I temps_arre & t temps_arret & t temps_Nvari & ritemps_G1_s & temps_Go_si \\
\hline 2 & 0 & 0 & 0 & 0 & 0 & 1.9 & 1.9 & 0 & 0 & ) $\quad 0$ & . 0 \\
\hline 3 & 0 & 2 & 0 & 0 & 1 & 27.2 & 6.3 & 19.9 & 0.1 & 0 & 0.9 \\
\hline 4 & 0 & 2 & 0 & 1 & 1 & 15.9 & 8.5 & 7.4 & 0 & 0 & 0 \\
\hline
\end{tabular}

Figure 8. Smart data file extract 
Show: $\checkmark$ this $\checkmark$ different

context

Found 10 uses of case_tool_failure

$\nabla$ case_tool_failure

case_tool_failure hascontext context_tool_failure

Individual: case_tool_failure

case_tool_failure haseffect effect_tool_failure

case_tool_failure hascause cause_tool_failure

case_tool_failure Type case

Usage: cause tool failure

Show: $\checkmark$ this $\checkmark$ different

Found 6 uses of cause_tool_failure

7 .. case_tool_failure

case_tool_failure hascause cause_tool_failure

$\checkmark$ cause_tool_failure

... Individual: cause_tool_failure

cause_tool_failure Type cause

Usage: context_tool_failure

Show: $\checkmark$ this $\checkmark$ different

Found 6 uses of context_tool_failure

$\checkmark$ case_tool_failure

case tool failure hascontext context tool failure

$\nabla$. context_tool_failure

Individual: context_tool_failure

context_tool_failure Type context

Usage: effect_tool failure

Show: $\checkmark$ this $\checkmark$ different

Found 6 uses of effect_tool_failure

$\uparrow$ case tool failure

case_tool_failure haseffect effect_tool_failure

$\checkmark$ effect_tool_failure

effect_tool_failure Type effect

individual: effect_tool_failure

Figure 9. Ontology instantiation.

an exceeding of the threshold of the 'Ub' criterion, and to recover all the necessary parameters.

The next step, 'searching for the cause', is the most important step, and is presented in the flowchart (see Figure 5) as a separate process.

Concerning this scenario, a fi st business rule was formalised following the interviews with the industrial partners of the project:

The tool is the cause of the breakage when the measured cutting conditions are different from the reference cutting conditions.

Here, measured cutting conditions are those recovered using the monitoring tools and the reference cutting conditions are the ideal ones predefine by the methods office.

To implement this rule at the ontology level, a transformation step is needed to convert this rule from the natural human language to the formalised rule language specifi to the JENA API, which is shown below:

@prefix ns: < SpecificPrefix $>$.

[rule1: (?a ns:hascontext?b)(?a ns:hascause?c)(?b ns:hastool?x)(?x

ns:hasVf?d)(?x ns:hasVFReal?w) notEqual(?d,?w)

$\rightarrow$ (?c ns:hascausedirect 'tool problem: non-compliant cutting condition')]

The execution of this business rule implies the verification and the comparison between the two categories 


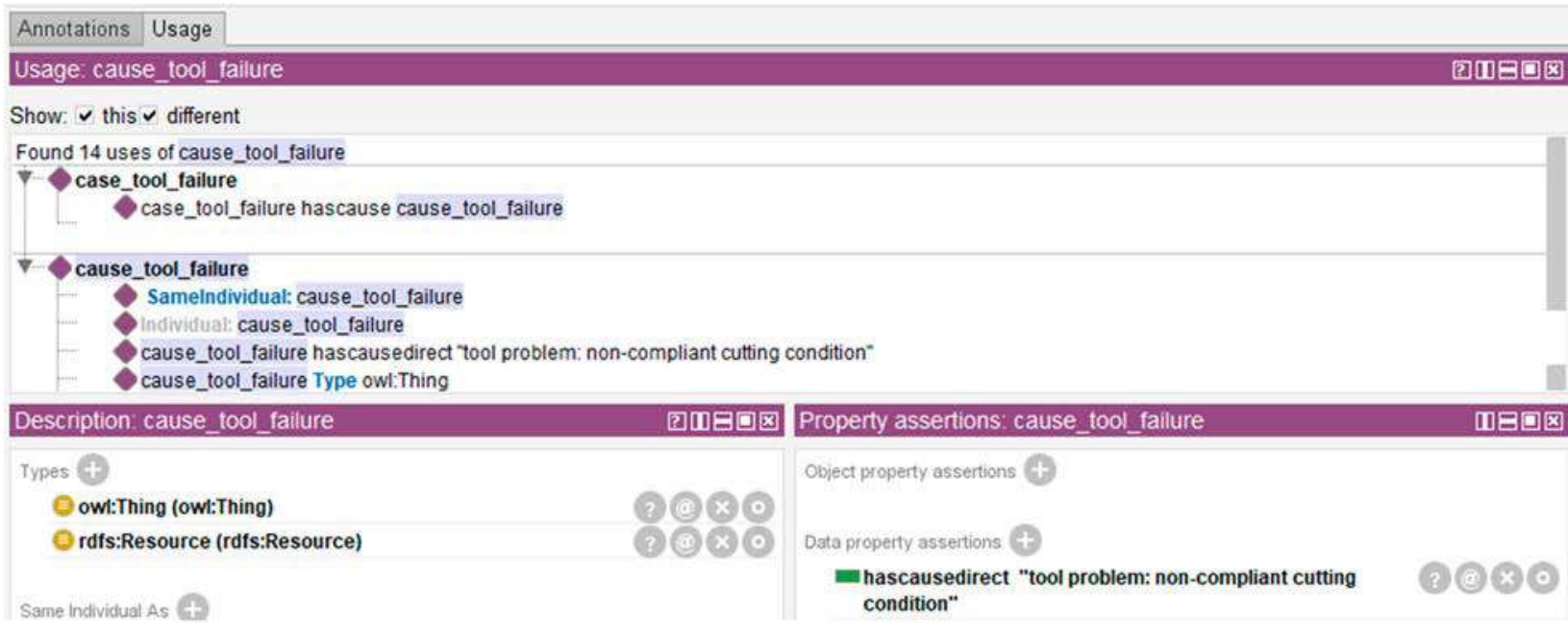

Figure 10. The Automatic instantiation of ontology.

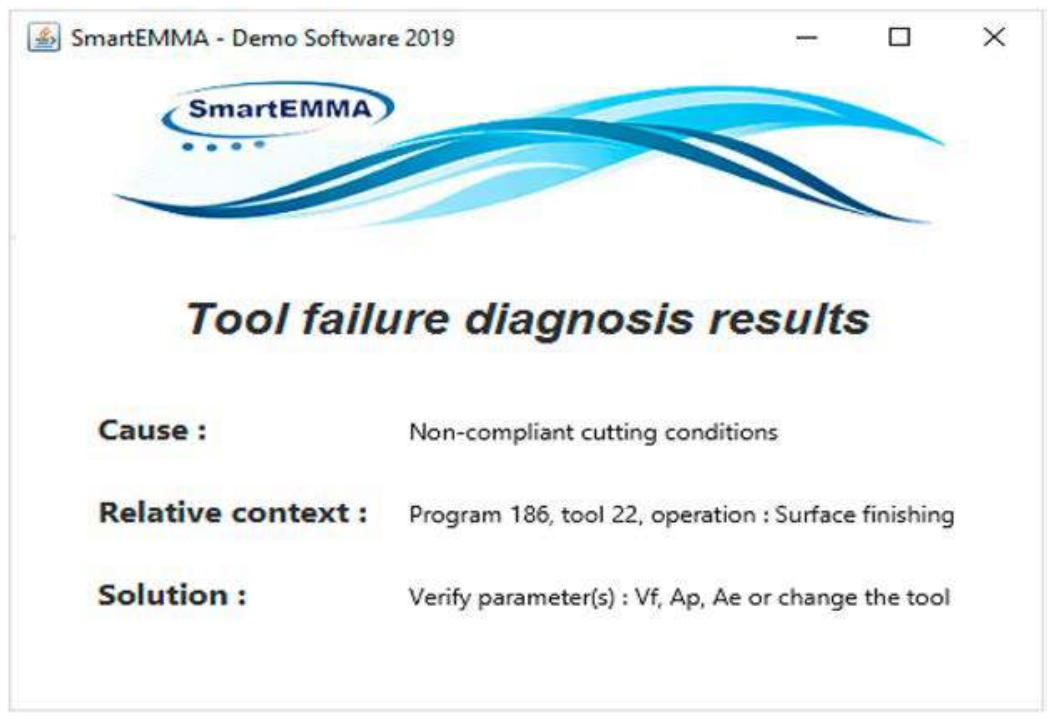

Figure 11. The final interface representing the result of the diagnosis.

of cutting conditions. In case of an inequality the individual 'Case_tool_failure' is instantiated and the cause is determined, as shown in the figure below where the cause was found to be 'Tool problem: non-compliant cutting condition' (Figure 10).

After the automatic instantiation of the ontology, the user receives the result of the entire diagnosis operation in the interface shown in Figure 11 and is presented with solutions.

This scenario represents a simple execution of a single business rule; other scenarios require multiple rules and iterations to fin the origin of a single problem. Therefore, a typical scenario would not necessarily end at this stage since the determination of a first direct cause can lead to a new diagnosis process for the determination of indirect ones.

\section{Conclusion}

The implementation of the industrial knowledge management methodology proposed in this article, and the testing of several decision-support scenarios have shown the feasibility and the interest of the approach. However, there are some limitations to this approach, most notably the availability and accessibility of industrial knowledge. Such a tool must be implemented in a favorable industrial context that offers the necessary resources and means, and encourages collaboration between the digital system and the experts. The complexity of the development is hence mainly focused on the formalisation of the business rules base, through the transformation of the expertise and all the implicit and tacit knowledge into explicit formal rules. This aspect favors and highlights the 
importance of the human place in the context of digitisation and the fourth industrial revolution. The need for a first phase of direct interviews with the business experts highlights this crucial role. In a nutshell, the challenge is to promote the importance of collaboration between the system and users who remain masters and controllers of the operations: the initial objective of a decision support system.

Our approach is specifi in its layered structure and especially the separation between the domain ontology layers that regroup the generic knowledge sets and libraries, and the decision support layer. This in turn guarantees adaptability and modularity in various other research domains by changing the first layer with another reference ontology of another field. In addition, the structuring of knowledge as a quadruplet 'ContextCause-Effect-Decision' would allow several perspectives for the development of the system. For example, the capitalisation of diagnosed cases and all the elements describing the work context would enables the elaboration of reasoning based on similarity indices. This would in turn facilitate future diagnosis operations, solution proposals, but also the prediction of the appearance of a phenomenon and the proposal of preventive actions.

Multiple perspectives could be envisaged for the continuation of this work. In the short term, the objective is to improve and enrich the business rules base, to be able to implement other diagnosis scenarios. Interviews with industrial experts continue to be held enabling the capitalisation of their expertise into an artificial intelligence embedded in the production machines. In this article, the use of the knowledge management methodology to implement a diagnosis process is demonstrated. Among the possible perspectives envisaged is the use of this strategy to implement other axes of decision support, especially, to provide reaction and prediction. Another perspective of this work consists in validating the adaptability and genericity of the methodology developed in other fields such as architecture and archaeology for example. This could demonstrate how the Context-Cause-Effect-Decision methodology is suitable on a comprehensive panel of knowledge-based diagnosis.

\section{Disclosure statement}

No potential conflict of interest was reported by the author(s).

\section{Funding}

This work was supported by Agence Nationale de la Recherche [grant number ANR-16-CE10-0005].

\section{Notes on contributors}

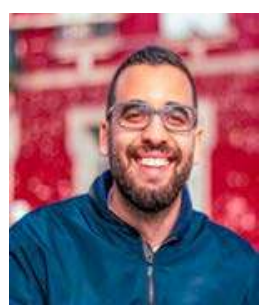

Dr Oussama Meski is a $\mathrm{PhD}$ student in industrial engineering at the University of Nantes (at LS2N: Laboratory of Digital Sciences of Nantes, IS3P team). $\mathrm{He}$ received his engineering degree in robotics in 2017 from the Polytechnic School of Montpellier France. Currently he is involved in the SmartEmma research project in which he is working on the challenges of digital transformation of companies and the industry 4.0 issues. He is mainly specialised in knowledge management for the development of decision support systems. Despite his very recent career in the field of scientific research, he has managed to publish his research in 3 international journals and several national and international conferences.

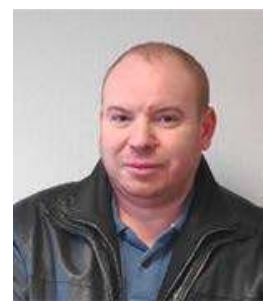

Dr Farouk Belkadi is an associate professor at Ecole Centrale de Nantes (researcher at LS2N laboratory, IS3P team). He received his $\mathrm{PhD}$ in Industrial Engineering from the University of Franche Comté in 2006. The $\mathrm{PhD}$ thesis treats the problematics of knowledge and skill management in design projects. During his career, he was involved in several research projects at national and European level, dealing with various topics: Product-service systems, system engineering, information systems and PLM, knowledge engineering and management, and, recently industry 4.0 related technologies. His research results were disseminated in 30 international journals and more than 70 national and international conferences

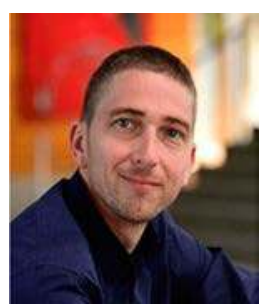

Dr Florent Laroche is assistant professor at Ecole Centrale de Nantes (France). After a engineering diploma in 2003 and his $\mathrm{PhD}$ in 2007, he was empowerment for driving his own researches in 2017. At university, Florent Laroche is the head of Mechanical Department for design and production product and system; Florent Laroche is doing his research at the laboratoryLS2N (Digital Science Laboratory, Nantes, France-UMR CNRS6004). He works on the translation of knowledge of the past in contemporary knowledge, readable and understandable in the present sociotechnical system. One objective of this research is to reuse the technical heritage as a basis for innovation. His research topics are KM, PLM, information system modelling, interoperability, enterprise modelling, virtual engineering, reverse engineering. $\mathrm{He}$ is active in 21 scientifi networks from all over the world. He is author, co-author or invited speaker in more than 230 scientifi communications quoted more than700 times; director of $12 \mathrm{PhD}, 26$ masters. He is expert for Museums and ICOMOS.

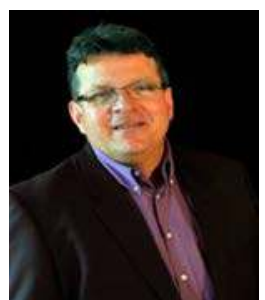

Pr Benoit Furet, after ENSM Nantes and MSc degree at E.N.S. Cachan, he became associate professor at the Institute of Technologies of the University of Nantes. In 1984, his $\mathrm{PhD}$ at LAN laboratory was about cutting tool monitoring in milling. Currently, he is a full Professor at University of Nantes and researcher in ROMAS group of LS2N Lab. He developed the following research topics: 
Robotics for machining, CFRP machining, Process Monitoring and Smart Machining. He has supervised $15 \mathrm{PhD}$ and 20 MSc Students. He has about 15 years of experience of collaborative research programs. He is involved in H2020 FoF02-16 COROMA and CleanSky2 RODEO projects. He is author or co-author of 38 articles and 3 patents. He is Expert member of the Jules Verne Research Institute of Technology. He is Assistant Vice President of the University of Nantes in charge of Innovation and Enterprises Relationship.

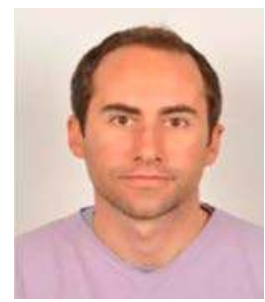

Dr Mathieu Ritou is Associate Professor of Mechanical Engineering at University of Nantes (IUT de Nantes) and LS2N lab (Laboratory of Digital Sciences of Nantes, UMR 6004, RoMaS research team). After a MSc degree and Aggregation at E.N.S. Cachan, his $\mathrm{PhD}$ at IRCCyN lab was about the monitoring of machining (2006). His research topics are Smart Manufacturing (decision aid by monitoring and data mining), spindle dynamics and CFRP cutting. He has supervised $11 \mathrm{PhD}$ and $8 \mathrm{MSc}$ students. He co-authored 17 articles in international journals and 40 conferences papers. He has 10 years of experience of collaborative research programs, notably project leader of ANR SmartEmma and participant to European H2020 FoF Coroma and CleanSky2 Rodeo projects. He is international expert at the ISO T.C.39/S.C.2. $\mathrm{He}$ is secretary of the association 'Club Usinage Innovation', which gathers the main French industrial and academic actors of the Factory of the Future in machining. He is Associate Member of the CIRP (the International Academy for Production Engineering), in Machine \& Organisation committees.

\section{ORCID}

Oussama Meski (D) http://orcid.org/0000-0002-3017-0954

Farouk Belkadi (D) http://orcid.org/0000-0003-2783-4147

\section{References}

Alavi, M., and D. E. Leidner. 2001. "Review: Knowledge Management and Knowledge Management Systems: Conceptual Foundations and Research Issues." Management Information Systems Quarterly 25 (1): 107-136.

Andersson, J., and P. Johnson. 2001. "Architectural Integration Styles for Large-Scale Enterprise Software Systems." Proceedings Fifth IEEE International Enterprise Distributed Object Computing Conference, Seattle, WA, USA, 224-236. doi:10.1109/EDOC.2001.950442.

Annamalai, G., R. Hussain, M. Cakkol, R. Roy, S. Evans, and A. Tiwari. 2011. "An Ontology for Product-Service Systems.” In Decision Engineering Report Series. Jürgen Hesselbach, Christoph Herrmann., edited by R. Roy and Y. Xu, 231-236. Berlin, Heidelberg: Springer. doi:10.1007/978-3-642-196898_41.

Archer, E. R. 1980. "How to Make a Business Decision.” Management Review 69 (2): 54-61.

Arnott, D., and G. Pervan. 2005. "A Critical Analysis of Decision Support Systems Research.” Journal of Information Technology 20. doi:10.1057/palgrave.jit.2000035.

Arp, R., B. Smith, and A. Spear. 2015. Building Ontologies With Basic Formal Ontology. Boston: MIT Press.

Belkadi, F., N. Dremont, A. Notin, N. Troussier, and M. Messaadia. 2012. "A Meta-Modelling Framework for Knowledge
Consistency in Collaborative Design." Annual Reviews in Control 36 (2): 346-358.

Berawi, M. A., and R. M. Woodhead. 2005. "Application of Knowledge Management in Production Management." Human Factors and Ergonomics in Manufacturing 15: 249-257.

Berners-Lee, T., J. Hendler, and O. Lassila. 2001. "The Semantic Web." Scientific American 284: 34-43.

Borsato, M. 2014. "Bridging the Gap Between Product Lifecycle Management and Sustainability in Manufacturing Through Ontology Building." Computers in Industry 65: 258-269.

Brynjolfsson, E., L. M. Hitt, and H. H. Kim. 2011. "Strength in Numbers: How Does Data-Driven Decision-Making Affect Firm Performance?" Social Science Research Network (SSRN). doi:10.2139/ssrn.1819486.

Carlsson, S., P. Brezillon, P. Humphreys, B.G. Lunberg, A. McCosh, and V. Rajkovic (Eds.). 2000. Proceedings of IFIP TC8/WG8.3 International Conference on Decision Support Through Knowledge Management. Stockholm, Sweden: Stockholm University/Royal Institute of Technology, Sweden.

Carlsson, S.A. and B.G. Lundberg. 2000 Preface and Introduction in Proceedings of IFIP TC8/WG8.3 International Conference on Decision Support Through Knowledge Management. Stockholm, Sweden: Stockholm University/royal Institute of Technology, Sweden.

Chow, H. K. H., K. L. Choy, W. B. Lee, and F. T. S. Chan. 2005. "Design of a Knowledge-Based Logistics Strategy System." Expert Systems Applications 29: 272-290.

Chryssolouris, G., D. Mourtzis, N. Papakostas, Z. Papachatzakis, and S. Xeromerites. 2008. "Knowledge Management Paradigms in Selected Manufacturing Case Studies." In Methods and Tools for Effective Knowledge Life-CycleManagement. Alain Bernard, Serge Tichkiewitch, 521-532. Berlin: Springer.

Chungoora, N., R. I. Young, G. Gunendran, C. Palmer, Z. Usman, N. A. Anjum, A. F. Cutting-Decelle, J. A. Harding, and K. Case. 2013. "A Model-Driven Ontology Approach for Manufacturing System Interoperability and Knowledge Sharing." Computers in Industry 64: 392-401.

Cochrane, S., R. I. M. Young, K. Case, J. Harding, J. Gao, S. Dani, and D. Baxter. 2009. "Manufacturing Knowledge Verific tion in Design Support Systems." International Journal of Production Research 47 (12): 3179-3204.

Cutting-Decelle, A. F., R. I. M. Young, J. J. Michel, R. Grangel, J. Le Cardinal, and J. P. Bourey. 2007. "Iso 15531 Mandate: A Product-Process-Resource Based Approach for Managing Modularity in Production Management." Concurrent Engineering 15 (2): 217-235.

Davenport, T., and L. Prusak. 1998. Working Knowledge: How Organizations Manage What They Know. Boston: Harvard Business Review Press.

Demoly, F., D. Monticolo, B. Eynard, L. Rivest, and S. Gomes. 2010. "Multiple Viewpoint Modelling Framework Enabling Integrated Product-Process Design." International Journal on Interactive Design and Manufacturing 4 (4): 269-280.

Drucker, P. F. 1958. "Marketing and Economic Development." Journal of Marketing Vol.22 (3): 252-259.

Efthymiou, K., K. Sipsas, D. Mourtzis, and G. Chryssolouris. 2015. "On Knowledge Reuse for Manufacturing Systems Design and Planning: A Semantic Technology Approach.” 
CIRP Journal of Manufacturing Science and Technology 8: 1-11. doi:10.1016/j.cirpj.2014.10.006.

Fankam, C. 2009. “OntoDB2: un Système flexible et Effici t de Base de Données à Base Ontologique Pour le Web Sémantique et les Données Techniques." PhD thesis. ENSMA, Futuroscope, France.

Farhoomand, A. F., and D. H. Drury. 2002. "Managerial Information Overload." Communications of the ACM 45 (10): 127.

Ferretti, S., D. Caputo, M. Penza, and D. M. D’Addona. 2013. "Monitoring Systems for Zero Defect Manufacturing." Procedia CIRP 12: 258-263. doi:10.1016/j.procir.2013.09.045.

Gernhardt, B., T. Vogel, M. Givehchi, L. Wang, and M. Hemmje. 2016. "Knowledge-Based Production Planning Within the Reference Planning Process Supporting Manufacturing Change Management." Manufacturing Science and Engineering Conference. doi:10.1115/MSEC2016-8658.

Godreau, V., M. Ritou, E. Chové, B. Furet, and D. Dumur. 2019. "Continuous Improvement of HSM Process by Data Mining." Journal of Intelligent Manufacturing 30 (7): 2781-2788.

Gorry, G. A., and M. S. Scott Morton. 1971. "A Framework for Management Information Systems." Sloan Management Review 13 (1): 510-571.

Grevenitis, K., F. Psarommatis, A. Reina, W. Xu, I. Tourkogiorgis, J. Milenkovic, J. Cassina, and D. Kiritsis. 2019. "A Hybrid Framework for Industrial Data Storage and Exploitation.” Procedia CIRP 81: 892-897. doi:10.1016/j.procir.2019.03. 221.

Gruber, T. R. 1993. “A Translation Approach to Portable Ontology Specific tions.” Knowledge Acquisition 5 (2): 199-220. doi:10.1006/knac.1993.1008.

Gruninger, M., and J. B. Kopena. 2005. "Planning and the Process Specific tion Language." In Proceedings of WS2 ICAPS 2005. Juan Fernández Olivares, Eva Onaindía, 22-29. Monterey, CA: ICAPS.

Gruninger, M., and J. Lee. 2002. "Ontology Applications and Design." Communications of the ACM 45 (2): 39-41. doi:10.1145/503124.503146.

Gunasekaran, A., and E. W. T. Ngai. 2007. "Knowledge Management in 21st Century Manufacturing." International Journal of Production Research 45 (11): 2391-2418. doi:10.1080/00207540601020429.

Gunendran, A.G., and R.I.M. Young. 2007. “An information and knowledge framework for multiple-perspective design and manufacture." International Journal of Advanced Manufacturing Technology 32 (5): 423-433.

Iaksch, J. S., and B. Milton Borsato. 2019. "Method for Digital Evaluation of Existing Production Systems Adequacy to Changes in Product Engineering in the Context of the Automotive Industry." Advanced Engineering Informatics 42. doi:10.1016/j.aei.2019.100942.

Kant, J., and S. Sridharan. 1998. "The Values of Using Scheduling Information in Planning Material Requirements.” Decision Sciences 29 (2): 479-497.

Klement, N., C. Silva, and O. Gibaru. 2017. “A Generic Decision Support Tool to Planning and Assignment Problems: Industrial Application \& Industry 4.0.” Procedia Manufacturing 11: 1684-1691.

Krima, S., R. Barbau, X. Fiorentini, S. Rachuri, and R. Sriram. 2009. “OntoSTEP: OWL-DL Ontology for STEP." In Proceedings of the International Conference on Product Lifecycle Management PLM'09.
Kulvatunyou, B., E. Wallace, D. Kiritsis, B. Smith, C. Will. 2018. "The Industrial Ontologies Foundry Proof-of-Concept Project: IFIP WG 5.7." In International Conference, APMS 2018, Seoul, Korea, August 26-30, 2018, Proceedings, Part II.

Labrousse, M., and A. Bernard. 2008. "FBS-PPRE, an Enterprise Knowledge Lifecycle Model." In Methods and Tools for Effective Knowledge Life-Cycle-Management. Alain Bernard, Serge Tichkiewitch, 285-305. Berlin: Springer. doi:10.1007/ 978-3-540-78431-9_16.

Lau, H. C. W., A. Ning, K. F. Pun, K. S. Chin, and W. H. Ip. 2005. "A Knowledge-Based System to Support Procurement Decision.” Journal of Knowledge Management 9 (1): 87100.

Lemaignan, S., A. Siada, J. Y. Dantan, and A. Semenenko. 2006. "Mason: A Proposal for an Ontology of Manufacturing Domain.” Distributed Intelligent Systems: Collective Intelligence and Its Applications, IEEE Workshop: 195200.

Masolo, C., L. Vieu, E. Bottazzi, C. Catenacci, R. Ferrario, A. Gangemi, and N. Guarino. 2004. Social Roles and their Descriptions. In KR (pp. 267-277).

McGuinness, D. L., and F. V. Harmelen. 2004. "OWL Web Ontology Language Overview.” http://www.w3.org/TR/ 2004/REC-owl-features-20040210/.

McLean, C., Y. T. Lee, G. Shao and F. Riddick. 2005. "Shop Data Model and Interface Specific tion." Technical Report NISTIR 7198. National Institute of Standards and Technology, Gaithersburg, Maryland.

Meski, O., F. Belkadi, B. Furet, and F. Laroche. 2019a. "Towards a Knowledge Structuring Framework for Decision Making Within Industry 4.0 Paradigm." IFAC-PapersOnLine 52 (13): 677-682.

Meski, O., F. Belkadi, F. Laroche, A. Ladj, and B. Furet. 2019b. "Integrated Data and Knowledge Management as Key Factor for Industry 4.0.” IEEE Engineering Management Review 47 (4): 94-100. doi:10.1109/EMR.2019.2948589.

Milicic, A., A. Perdikakis, S. ElKadiri, and D. Kiritsis. 2013. "PLM Ontology Exploitation Through Inference and Statistical Analysis A Case Study for LCC." IFAC Proceedings Volumes 46 (9): 1004-1008. doi:10.3182/20130619-3-RU-3018. 00043.

Miltner, F., T. Vogel, and M. Hemmje. 2014. “Towards Knowledge Based Process Planning Support for CAPP-4-SMEs: Problem Description." Relevant State of the Art and proposed approach", International manufacturing Science and Engineering Conference (MSEC).

Munir, K., and A. Anjum. 2018. "The use of Ontologies for Effective Knowledge Modelling and Information Retrieval." Applied Computing and Informatics 14 (2): 116-126. doi:10.1016/j.aci.2017.07.003.

Muthu, S., S.R. Devadasan, P. S. Mendonca, and G. Sundararaj. 2001. "Pre-auditing through a knowledge base system for successful implementation of a QS 9000 based maintenance quality system." Journal of Quality in Maintenance Engineering 7 (2): 90-104. doi:10.1108/13552510110397 386.

Oberle, D., A. Anupriya, H. Pascal, C. Philipp, S. Michael, K. Malte, M. Babak M, et al. 2007. "DOLCE Ergo SUMO: On Foundational and Domain Models in the SmartWeb Integrated Ontology (SWIntO)." Journal of Web Semantics 5 (3): 156-174. 
Octaviani, D., A. Pranolo and S. Othman. 2015. "RDB2Onto: An Approach for Creating Semantic Metadata From Relational Educational Data." 2015 International Conference on Science in information Technology, Yogyakarta: 137-140.

Olson, D. L. 2018. "View of IJPR Contributions to Knowledge Management in Supply Chains." International Journal of Production Research 56 (1-2): 733-742. doi:10.1080/00207543. 2017.1398427.

Olson, D. L., and D. Wu. 2017. Predictive Data Mining Models. Singapore: Springer.

Palmer, C., Z. Usman, O. Canciglieri Jr, A. Malucelli, and R. I. M. Young. 2018. "Interoperable Manufacturing Knowledge Systems." International Journal of Production Research 56 (8): 2733-2752. doi:10.1080/00207543.2017.1391416.

Panetto, H., M. Dassisti, and A. Tursi. 2012. "Onto-pdm: Product-Driven Ontology for Product Data Management Interoperability Within Manufacturing Process Environment." Advanced Engineering Informatics 26: 334-348.

Psarommatis, F., G. May, P. A. Dreyfus, and D. Kiritsis. 2019. "Zero Defect Manufacturing: State-of-the-art Review, Shortcomings and Future Directions in Research." International Journal of Production Research 58 (1): 1-17.

Raman, A., K. Haapala, K. Raoufi, B. Linke, W. Bernstein, and K. Morris. 2020. "Defining Near-Term to LongTerm Research Opportunities to Advance Metrics, Models, and Methods for Smart and Sustainable Manufacturing." Smart and Sustainable Manufacturing Systems 4. doi:10.1520/SSMS20190047.

Ramis, B., B. Ahmad, D. Vera, A. Lobov, R. Harrison, and J. L. Martínez Lastra. 2016. "Product, Process And Resource Model Coupling For Knowledge-Driven Assembly Automation." Automatisierungstechnik 64: 3.

Ritou, M., F. Belkadi, Z. Yahouni, C. Da Cunha, F. Laroche, and B. Furet. 2019. "Knowledge-based Multi-Level Aggregation for Decision aid in the Machining Industry." CIRP Annals 68 (1): 475-478. doi:10.1016/j.cirp.2019.03.009.

Sanfilippo, E. M., and S. Borgo. 2015. "Feature-Based Modelling and Information Systems for Engineering." $A I^{\star} I A$ 2015 Advances in Artificial Intelligence. Lecture Notes in Computer Science Vol 9336: 151-163. Springer.

Sanya, I. O., and E. M. Shehab. 2015. “A Framework for Developing Engineering Design Ontologies Within the Aerospace Industry." International Journal of Production Research 53 (8): 2383-2409.
Schlenoff, C., M. Gruninger, F. Tissot, J. Valois, J. Lubell, and J. Lee. 2000. "ISO-18629 The Process Specific tion Language (PSL): Overview and Version 1.0 Specific tion, NISTIR 6459." National Institute of Standards and Technology, Internal Report.

Schmidt, J., M. Borsato, E. Hinckel, F. Maccari, P. Storrer and E. Onofre. 2016. "A Framework for Capturing and Applying Design Knowledge in Complex Systems.” International Conference on Transdisciplinary Engineering, Curitiba, Brazil.

Shim, J., M. Warkentin, and J. Courtney. 2002. "Past, Present, and Future of Decision Support Technology.” Decision Support System 33: 111-126.

Simon, H. A. 1959. "Theories of Decision-Making in Economics and Behavioral Science." In The American Economic Review. Vol. vol. 49, no.3, 253-283. Nashville: American Economic Association.

Sureephong, P., N. Chakpitak, Y. Ouzrout, and A. Bouras. 2008. "An Ontology-basedKnowledge Management System for Industry Clusters.” International Conference on Advanced Designand Manufacture, China.

Teti, R. 2015. "Advanced IT Methods of Signal Processing and Decision Making for Zero Defect Manufacturing in Machining." Procedia CIRP 28: 3-15.

Urwin, E. N., and R. I. M. Young. 2013. "The reuse of machining knowledge to improve designer awareness through the configur tion of knowledge libraries in PLM." International Journal of Production Research 52 (2): 595-615. doi:10.1080/00207543.2013.839894.

Vrba, P., M. Radakovič, M. Obitko, and V. Mařík. 2011. "Semantic Technologies: Latest Advances in Agent-Based Manufacturing Control Systems." International Journal of Production Research 49 (5): 1483-1496. doi:10.1080/00207543.2010. 518746.

Wang, Z., C. Da Cunha, M. Ritou, and B. Furet. 2019. “Comparison of K-Means and GMM Methods for Contextual Clustering in HSM." Procedia Manufacturing 28: 154-159. doi:10.1016/j.promfg.2018.12.025.

Zsidisin, G. A., S. A. Melnyk, and G. L. Ragatz. 2005. “An Institutional Theory Perspective of Business Continuity Planning for Purchasing and Supply Management." International Journal of Production Research 43-16: 3401-3420. doi:10.1080/00207540500095613.

Zuehlke, D. 2010. "Smartfactory-towards a Factory-Ofthings." Annual Reviews in Control 34 (1): 129-138. 